\title{
The Complexities of Technology-Based Care: Telecare as Perceived by Care Practitioners
}

\author{
Andrew Eccles \\ School of Applied Social Sciences, University of Strathclyde \\ Glasgow, United Kingdom \\ E-mail: andrew.eccles@strath.ac.uk
}

Received: September 21, 2013 Accepted: October 11, 2013 Published: October 25, 2013

doi:10.5296/iss.v1i1.4464 URL: http://dx.doi.org/10.5296/iss.v1i1.4464

\begin{abstract}
Telecare, which offers 'care at a distance' (Pols, 2012) through a variety of remote monitoring technologies, has developed rapidly across health and social care policy in many developed countries. Nonetheless, approaches to this development differ; the focus of this paper is the United Kingdom, where implementation has been particularly rapid and ambitious in scope. The paper argues that, while there are clear and tangible benefits from the use of some telecare technologies, there is insufficient research about the complexities of implementation with end users. These complexities include ethical questions raised by the use of monitoring and surveillance equipment, the ability to fine tune technologies to the needs of individuals, and the way in which care relationships may be altered by remote care mediated through technologies. This paper addresses these issues through a particularly under researched area; that is, the perceptions of care practitioners who assess for, and interact with, these technologies. The research was conducted with practitioners using qualitative research methodology. The paper concludes that Telecare practice is uneven in the way it addresses complexities and that more needs to be done to understand the way in which technologies are discussed and utilised by those charged with their implementation.
\end{abstract}

Keywords: telecare, care technologies, health care, social care, public policy 


\section{Care Technologies Policy}

Recent years have seen a substantial interest, particularly in developed countries, in the use of technologies which allow 'care at a distance' (Pols, 2012) in the delivery of health and social care. These technologies are geared towards the perceived health and care needs of different client groups - such as older people, disabled people and people with long term conditions - and are widely assumed by technologists and change managers in health and social care to have the capability to impact beneficially on clients' lives. Of these clients, older people are the most likely recipients - given their care needs but also because demographic change and attendant costs are rarely far from the discussion on these technologies - although their use extends to a wide range of people with disabilities across age groups. These technologies have developed rapidly in the past decade from a 'first generation' of basic alarms, detectors and passive sensors in houses, to current manifestations such as the monitoring of long term health conditions and tracking movement in people's homes. In its more recent guises, using GPS based technologies, telecare technologies can track the movements, and health status, of people outside their home environments, thus allowing people's lifestyles to continue despite, for example, the onset of memory loss, other cognitive impairment, or chronic conditions of ill-health. These technologies now cover social care, health care and rehabilitation, spawning the use of the (often imprecise and overlapping) categories telecare, telehealth and telerehabilitation. There is some merit to these demarcations but, following an approach more likely to be favoured in continental Europe (see for example Pols and Willems, 2011), this paper uses telecare as an umbrella term for these different aspects of care technologies in their application to people's - often overlapping - health, social care and rehabilitation needs.

The United Kingdom (UK) has been perceived - and styles itself - as a world leader in the use of these technologies (Department of Health, 2012a). Of the UK's component parts, the State funded and organised health care service in England, on the assumption that these technologies are cost effective and credible, launched the 3 millionlives programme in 2011, with the aim of having three million people using telecare and telehealth by 2017 (DoH, 2012b). Most of this group are projected to be older people. Scotland, regarding itself a world leader in this field, is building on its initial programme from 2006, which proposed that by the year 2015: 'all new homes, public and private, and all refurbished social housing, will be fitted with the capacity for care and health services to be provided interactively via broadband from day one of occupation' in which 'remote long term condition monitoring undertaken from home will be the norm' (Scottish Government, 2008, p.6). This, in turn, puts the telecare programmes being implemented across the United Kingdom at the forefront of a broader European Union engagement with a digital future (see, for example, e-care benchmarking across the European Union (European Commission, 2013)) and European programmes looking at attendant features of telecare policy, such as ethical frameworks in the use of telecare technologies (EFORTT, 2012).

There is evidence of benefits to be derived from the use of telecare technologies. For service users these benefits include greater continued independence, autonomy and enhanced connectivity with others (Blaschke, Freddolino, \& Mullen, 2009; Loader, Hardey, \& Keeble, 2009; McCreadie \& Tinker, 2005; Moser, 2012; Pols, 2012; Steyaert \& Gould). There is also evidence of advantages for carers, particularly with reducing pressure on caring roles and 
alleviating isolation (Yeandle \& Fry, 2010). Apart from benefits to individuals and carers, financial savings generated through the use of telecare technologies could release funds for other applications, thus offering opportunities for better targeting of resources. As the Audit Commission - guardian of public finance expenditure in the UK - noted at the outset of telecare development, the use of these technologies represents the unusual possibility of providing cost savings at the same time as better service provision (Audit Commission, 2004). Subsequent to the Audit Commission report both governments in the UK and technology companies have explicitly promoted the move to telecare technologies based on two factors; increased cost savings and enhanced quality of life (see Eccles, Damadoran, Hardill, Olphert, \& Gilhooly (2013) for a wider discussion).

Since the Audit Commission offered its sanguine outlook on the use of these technologies a substantial critical literature has emerged. This literature has broadly focused on a lack of engagement with the wider social impact of telecare and reservations about the decision making processes involved in the scale of telecare programmes - what Mort, Roberts and Milligan (2009: 85) argue is an 'ethical and democratic deficit in this field which has arisen due to a proliferation in research and development of advanced care technologies that has not been accompanied by sufficient consideration of their social context'. Their comment is made also in the context of the United Kingdom's particularly ambitious and government driven policy agenda, an approach noted by Pols and Willems (2011:6), who argue that, in coming to terms with these technologies,

'The dubious status of promises and the unpredictable processes of domestication that are so hard to trap with standard research methods, make implementing telecare technologies on a large scale and on a top-down basis, as is done in the UK, a hazardous investment'.

The overriding hazard to which these authors allude is that the interaction between telecare technologies and their end users is complex and requires implementation based on appropriateness of purpose, nuance in understanding and fine adjustment to end-user needs. Pols and Willems' assessment is based on their extensive research with users of telecare technologies in the Netherlands. Their findings are echoed in research from Finland (Soderlund, 2004), Norway (Moser, 2012), Spain (Mort, Roberts, \& Callen, 2013) from further research on the situation in the Netherlands (Oudshoorn, 2011; Pols 2012; Kamphof, 2013) and from research by Greenhalgh et al (2013) in the UK, a deeply rich phenomenological enquiry into service users' experience of care technologies. These studies note the potential benefits from the use of these technologies but at the same time uncover unanticipated complexities in their implementation, which requires attention to small scale specifics of how individual users perceive of, and function with, these new technologies. This complexity in practice requires space for debate and reflection, neither of which emerges easily in the ambitious scale of government sponsored telecare policy to be seen in the United Kingdom. The hazard, then, is in understanding and responding to the quality of the care experience for users of telecare services. In a policy world of fiscal scarcity and reduced social care bud gets (see Mort, Roberts \& Callen (2013) on telecare use in an era of austerity), it has been assumed there may be distinct gains from the use of telecare technologies for governments and policy officials charged with reducing costs, one of the reasons why policy implementation has moved rapidly. This has 
encountered a further potential hazard, in that this push for such high levels of telecare engagement, representing, as it does, often profound shifts in types of care and care relationships, comes against a backdrop of very low recognition by the public of the telecare and telehealth arena; a 2012 survey of UK adults (Lintern, 2012) indicated that $91 \%$ had not heard of either telecare or telehealth. Of those surveyed who were aged 55 or over - the most likely recipients of these technologies - 93 per cent had heard of neither. The evidence from other European countries is that telecare technologies work in some contexts, with some people at some stages in their lives, a sentiment which is increasingly emerging from researchers looking at the UK experience (Eccles, 2010, April; Newman, 2011; Greenhalgh et al, 2013). The contrast between this uncertainty about outcomes using telecare technologies with the policy position of UK governments is clear, whether with the ambitions of the 3 millionlives programme in England or the commitment from the Scottish Government that 'telehealth will be widely recognised by service users and their carers as the route to greater independence and quality of life' (Scottish Government, 2008, p. 6).

\section{Recent Trial-Based Research}

The scale of ambition for the use of Telecare technologies in the United Kingdom is illustrated by the Whole System Demonstrator (WSD) project, the largest telecare research programme undertaken anywhere in the world to date at a cost - funded by the UK government - of $£ 31 \mathrm{~m}$. (Goodwin, 2012). This project has variously involved a randomised control trial (RCT) of telehealth and telecare users across three sites in England, with data collection over twelve months and analysis over a further twelve. The results of this research have come after the announcement of the ambitious policy proposals outlined above. It is not in the remit of this paper to explore the WSD results in detail; suffice it to say the first three tranches of WSD reporting between 2012 and 2013 offer results on cost savings and quality of life enhancement which are not clear cut, sometimes at odds with current policy, and open to debate (Cartwright et al, 2012; Innes, Morice, \& Faruqi, 2012). Despite this, the UK policy world moves on: the telecare programme in Scotland, in its latest guise projecting forward to 2020, notes the need to: 'Maximise and increase the use of telehealth and telecare to improve access for citizens to planned and unplanned care' (Scottish Government, 2012, p. 26), whilst the UK Prime Minister, speaking in December 2012, announced of the telecare programme: 'We've trialled it, it's been a huge success and now we're on a drive to roll this out nationwide' (Cameron, 2011). This rather sweeping announcement was made on the basis of claims by the UK Department of Health involving, as Greenhalgh (2012: 344) notes, the 'cherry-picking of unanalysed data to put on its website before the trial had finished recruiting [which] was scientifically inappropriate but politically expedient'. The political expediency reflects the decision to undertake an ambitious telecare program without a sufficient evidence base but perhaps also reflects a powerful nexus between governments in the UK and technology companies.

These complexities and tensions between telecare policy and practice go beyond the experiences of just service users. A distinctly under- researched area has been the experience of carers and care workers, who will increasingly be expected to engage with these new technologies. There is unpredictability here across various fronts. There may be differences in attitude across age groups which are more or less familiar with new technologies, but also across different caring professions - for example health and social care - which are now 
expected to as sess older people for the potential of using technology based care, and between family members and technology recipients over the suitability of these technologies. Thus, while monitoring equipment may offer extended families and carers peace of mind, it may simultaneously represent an intrusion into the privacy of recipients; what we have here is the need for more qualitative research on the actual experience of care professionals, carers and clients in understanding how, when and why these technologies are used and how the various parties to their use experience them. There exist limited, and essentially surface, accounts of client satisfaction (see, for example, Scottish Government, 2009) but a paucity of research based on more depth of enquiry. Where these deeper case studies do exist - particularly from the Netherlands, but also Moser's (2012) work in Norway - they point to the complexity of operationalizing telecare technologies and the intricate, often unpredictable consequences of the interface between technologies, their users and care practitioners. Both Oodshourn (2011), and Kamphof (2013a), offer findings from research with carers and practitioners which adds further layers of complexity. This is particularly the case with the second and third generation telecare technologies (which provide copious data from the monitoring of service users in their own homes or via GPS) where sifting the data and responding to its implications may be approached quite differently by different carers and care professionals, giving rise to new concerns about the responsibilities of care professionals who have access to data but may be overloaded by its sheer volume. Kamphof also notes the tensions that arise between practitioners and their managers, where practitioners feel confident to sift (and thus order) data in the face of more managerialist concerns (see Meagher \& Parton, 2004, for a discussion of this tension), that all data should be recorded and interpreted. Some of this sifting will be professional discretion based on, perhaps tacit, knowledge over what data is worth noting; other sorting may be an attempt to make the scale of data more manageable (Kamphof, 2013, May). Moser's work with carers points to a similar set of issues; whilst it is often carers and family members who feel a particular benefit from technologies that are keeping their relatives' movements and health condition monitored, this carries unforeseen additional pressures: checking equipment, interpreting movements and having additional care responsibilities (Moser, 2012). There is thus an increasing amount of qualitative research evidence of complexity in the use of these technologies. It is worth noting that the findings from the Whole System Demonstrator research, noted above, prompted the WSD authors - specifically in their exploration of quality of life measurement - to recommend the need for more qualitative research enquiry in the UK context, as it is often the specific contexts in which decisions about telecare technologies are being made that are crucial to recipients receiving technologies appropriate to their lives.

\section{Ethical Practice and Care Relationships}

As has been noted, these advanced generation care technologies may use multiple sensor points in a person's home; these may be passive infra-red sensors or bed sensors that react to absence or movement. These sensors are used to monitor and record a pattern of behaviour for the client, such that deviations from this pattern in future may trigger an alert with those who are engaged in the remote monitoring. This takes us into uncharted territory on the ethics front in terms of social care. The ethical guidance being deployed in the use of these new technologies often does not mirror the sophistication of this new technological terrain, nor adequately recognise 
its implications. Indeed the ethical angle is often absent, or of limited relevance, in policy discussions around this increased use of assistive technologies (see Eccles, 2010b for a summary). This might be explained by the fact that different professions which engage in human services already have ethical codes of practice (albeit the codes themselves are then open to interpretation), reflecting the practical reality that ethical frameworks have to be understood by practitioners and that their terminology has to resonate with the care assessment process (Bouma, 2010). But are these codes enough to deal with rapid and innovative technological change? And are the codes of practice themselves bound by a particular regulatory paradigm of what constitutes 'good practice' which does not allow adequate space for reflection or challenge to the received wisdom of professions themselves (Tronto, 2010) in a more technological era? There may therefore be very different understandings about appropriate and ethical use of technologies across different professions. These differences in understanding take on a broader significance when other parties to the use of telecare are considered. Greenhalgh, Procter, Wherton, Sugarhood and Shaw S (2012) examine the different discourses around telecare technologies where technologists, change managers and front line practitioners might have very different understandings of what these technologies can achieve or how care relationships might be altered by their use. While their argument alights particularly on the overly ambitious claims of technologists, these different understandings of what technology can do might manifest themselves adversely for clients in reluctance by social care professionals to engage with the more advantageous possibilities of technology. This is because care workers are themselves invested in the relational aspect of the work they do, or perceive an absence of a human relationship in a care setting to be inherently less desirable. Thus there is a need to guard against assumptions that technologically based care is inherently inferior to care based on human relationships. As Pols and Moser (2009) argue "In discussions about the use of new technologies in health care, including the most recent versions appearing as 'Telecare', there is the fear that cold technologies will be implemented at the cost of warm human care" (p. 160) and note that "there are different relations between people and technologies within different use practices allowing different affective and social relations" ( $p$. 159). A further false dichotomy exists in positioning human based care against its technological counterpart; in practical policy terms there is not a level playing field in which ideal technologies can be enlisted alongside ideal forms of human relationship based care. The Equality and Human Rights Commission (EHRC, 2011) enquiry into home care provision in the United Kingdom suggests human care services are often impersonal, very time-limited and inconsistent, in which the potential for the kind of relationships which have been held in high esteem by care professionals to develop between carers and service users appears to be increasingly remote. Nonetheless the use of technologies will reshape the relationships of care as they have been known hitherto; care relationships for clients will be with the technologies in their homes and whoever responds to the information generated by these technologies (for example patterns of movement and sleep or monitoring of key body functions). These developments imply a radical change to the character of the home - that is, a space which has been traditionally regarded as safe, secure and private (Twigg, 1999) into a site that is increasingly one of medicalization. Of course some monitoring technologies may be a supplement to continuing visits by care workers. In this situation the technology will still be in 
place in the service users' homes, able to detect with some precision the movement of care workers as they attend to their tasks; the technology thus also represents a form of surveillance of the workforce which had hitherto not existed but may formalise care giving more towards routine tasks being seen to be carried out.

Mediating between the broader policy agenda and practice on the ground are locally based operational managers in health and social care settings who inhabit a world of increasing care needs, especially amongst older people, and declining per capita care budgets. This adds a further layer of complexity to decision making around the use of care technologies. Mort, Roberts and Callen (2013) draw on their observational work of telecare operational managers in noting how perceived misuse of these technologies may lead to their withdrawal from clients who are in receipt of them. This misuse would typically involve using the interactive technology for a social, rather than medical, conversation with an operator in a monitoring centre. This is not what the technology was intended for; but by whose calculation is it misuse? From the perspective of a technologist or change manager it may be; but from a carer or user perspective it is likely to highlight the older person's desire for social connection (and thus trigger the sign of potential isolation in their own home) or a basic misunderstanding about the purpose of the technology, not least as recipients may often have a disability such as dementia. Mort, Roberts and Callen also recount the underuse of telecare technologies, for a variety of reasons, by recipients (or perhaps under the social pressure of family and friends who do not understand them); a phenomenon which does not sit squarely with the more rationalist assumptions of technologists and technology companies about their use (see Greenhalgh et al, 2012, for a fuller discussion of these competing discourses). Indeed, as Draper \& Sorrell (2012: 8) note 'Although monitoring may provide peace of mind for carers, it may be perceived differently by users. In particular, it may be perceived as a threat to autonomy and independence'.

To sum up; telecare technologies offer well documented benefits to their clients. But on the basis of an increasingly sophisticated understanding of the complexity of their use, of the ethical questions raised by surveillance technologies, and of the new and unpredictable nature of changes in relations of care between carers and users, the ambitious claims of governments and technology companies around cost savings and enhanced quality of life would appear to be in tension with the complexities of actual care technologies practice.

\section{The Engagement of Practitioners with Remote Care Technologies}

Against this canvas of the current policy framework and state of play in research, this paper now turns attention to the area, noted above, which is particularly under-researched in the United Kingdom: how front line practitioners engage with telecare technologies. It draws on an original case study carried out across three telecare partnerships (which are largely based on local authority geographic areas) in Scotland. Although Scotland has had its own telecare development strategy, as befits a separate political jurisdiction, it shares, as has been indicated already, a similarly ambitious policy approach with the rest of the United Kingdom, and themes arising from the research here have had clear resonance subsequently amongst front line practitioners utilising these technologies in other parts of the United Kingdom. 


\subsection{Research Methodology}

Interviews were conducted with front line staff and telecare project managers across three 'telecare partnership' sites in Scotland. The sites were based on a convenience sample of telecare partnerships which expressed an interest in being involved in the research following an invitation to the thirty two partnerships in Scotland. They represent, based on the Scottish Government Urban/Rural classification 2009-10 (Scottish Government, 2010) one urban site (U) which was previously highly industrialised, and has high indicators of social deprivation, and two predominantly rural settings with some urban clusters (R1\&R2). Front-line interviewees were variously drawn from social work and social work managers $(\mathrm{SW}, \mathrm{SW}(\mathrm{m}))$, occupational therapy (OT) community nursing $(\mathrm{CN})$, health care assistants (HCA), housing officers (HO), technicians (T) and technology advisors (TA). All three sites were at different stages of development; site $U$ had had a longer established telecare strategy which predated the current Scottish Government telecare development programme, site R1 had developed more recently, while site $\mathrm{R} 2$ was at a formative stage in its telecare development. While all three sites were evolving their own strate gies, they were each nonetheless subject to the performance indicators set for telecare partnerships by the Scottish Government (Scottish Government, 2009). This pattern of telecare partnerships was typical of the whole; uneven investment and different stages of development.

The study is limited in scale, exploratory and non-generalisable. But as Rourke notes, studies such as this are 'a model for the acquisition of fundamental information' (Rourke et al., 2001, p. 8) on which further research enquiry and research questions might be built. Ethical clearance to conduct the research involving human subjects was granted by the Ethics Committee of the University of Strathclyde. Some of the inquiry was linked to the literature reviewed above; other aspects were more exploratory, as befits research in a new area. The common denominator across the sample of interview participants was their role as assessors for the use of telecare technologies or advisers on the use of telecare equipment. The findings are essentially a 'snapshot' (Henwood, 1994) of telecare practitioners' views at a given point, being a sample total of twenty people interviewed in and around 2010. The interviews were supplemented by a number of discussions with front line practitioners based on opportunistic samples across social work and health care settings; the results resonate strongly with subsequent discussions with practitioners through, for example, the author's engagement with the ESRC Making Research Count programme between participating universities and the world of practice in the United Kingdom. Interviews were recorded with interviewee consent and partially transcribed before being analysed for key information (drawing on Miles and Huberman, 1994; Rapley, 2011) around the themes of the interview inquiry. This inquiry addressed three broad areas which have featured prominently in the policy discourse in the United Kingdom and in the attendant critical literature discussed so far in this paper, viz.; how the reasons behind the implementation of telecare technologies were understood by practitioners; perceived advantages or disadvantages of telecare for service users; the way in which telecare might reconfigure the idea of care relationships and issues around equity (for example, the accessibility and cost of technologies). Although two of the three sites had explicit guidelines on ethical practice, with a third having guidelines in preparation, a pilot study prior to the interviews revealed that more specific questions around ethical issues might 
prove difficult for interviewees, as staff in the pilot study were not confident about discussing ethical principles in any particular detail. This is an interesting finding in itself, and points to the possibility - as one telecare project manager noted - of a set of ethical guidelines on paper that may lack ease of transfer into front line practice (see Eccles, 2010a, for a fuller discussion on Telecare ethics). An additional theme around the performance indicator regime set out by the Scottish Government was addressed only to the project managers.

\section{Findings and Discussion}

\subsection{Telecare Policy Aims}

The rationale behind telecare was variously described by interviewees as facilitating 'independence and choice' (for example, OT/U, HO/R1), 'fitting in best with what people want' (SW/R), but also recognised by some as a response to demographic change. Front line professionals emphasised aspects of increased autonomy that telecare technologies might afford service users and they could discuss detailed examples of clients whose lives had been impacted thus. Potential cost savings also emerged as a theme:

A lot of it is about cost...once set up technology can replace the personal contact...then a saving to the department....also in some cases I imagine more efficient....in some cases less intrusive (HCA R2).

Interviewees also noted that the se cost savings could be justified in terms of the funding they could release; for example, carers who traditionally had stayed in the houses of vulnerable people could be replaced by monitors and bed sensors which would trigger an alert if 'unusual' activity was observed. For some respondents cost was a primary factor. Others noted the potential of technologies to offer continued independence for clients but offered the caveat about changes to service delivery.

'in theory absolutely great .... sincerely hope not used to cut services' (TA/R2).

Respondents also noted the potential for tensions between service users and carers, noting that the use of technology might result in a successful outcome for one party but not necessarily another, viz., discussing family carers,

'they want what's best ...it's quite difficult ...difficult for them to understand you can't just go ahead...some of the time it's about their anxieties.... I go between two camps' (HCA R2).

In this discussion on the objectives of telecare policy, safety emerged as a major theme especially across the two rural sites. A telecare assessor in site R1 noted that CCTV cameras were now a familiar feature of town centres in the United Kingdom and that monitoring equipment in people's homes was similarly geared towards safety. This was argued as a continuum, without reflection on public and private spaces represented here and the breaching of the latter. At the other rural site, R2, a similar theme emerged:

'where people don't have insight or capacity to make their own decisions....you want to keep the person safe... has to be [about] protection' (HCA/R2).

This theme of protection raised the ethical question of the balance between security and privacy, frequently played out in individual decision making around technology use. Most interviewees had some sense that there was a potential tension here although were unable to articulate this more specifically in terms of ethical codes or codes of practice. Some 
practitioners were frank in their accounts of how this tension played out, such as in this exchange (TA/R2) on how monitoring technologies might be fitted to an older person's hous e: '[Son or daughter would be] taking client out for coffee while [a technician] puts the equipment in

Interviewer: Does this happen?

TA/R2 Oh yeah yeah...with someone's relatives...

Interviewer: [Is there] consent through the relatives?

$\mathrm{TA} / \mathrm{R} 2$ Yes

Interviewer: Do they have power of attorney?

TA/R2 Probably not [pause] maybe not, I would very much doubt it [pause] keeping someone safe is very important'.

At this site, R2, training sessions for staff on the use of these technologies had concentrated specifically on the potential advantages they might bring. There had been no discussion of around fiscal tensions or the ethical implications of employing technology based care. Yet all three telecare project managers across the different sites were aware of the financial agenda in which these technologies were being introduced and - in response to the interview question on what was driving the telecare project - had noted financial pressures as a key driver. This is an interesting finding. A more open discussion with practitioners who assess for the use of technology as part of care needs (there is now a dedicated section on needs assessment forms for this purpose) about the fiscal pressures behind telecare implementation might lead to practitioners reflexively questioning the ethics of technology based care.

\subsection{Do Telecare Technologies Reconfigure the Idea of Care?}

Interviewees were asked if particular types of delivery of care - for example involving a human presence or remote monitoring - could be distinguished as being qualitatively of a different order, encapsulated in the Pols and Moser (2009) notion of 'warm care' versus 'cold technology'. This enquiry raises the potential that differences in attitudes could, consciously or otherwise, impact on the willingness of practitioners to engage with, or resist, the use of telecare. No common theme emerged here; the project manager in the urban site had concerns about loss of human relationships if these technologies were 'used inappropriately' - which may link to the wider acknowledgement by project managers of the financial drivers discussion behind telecare policy. Other interviewees viewed telecare technologies as essentially neutral: thus,

'technology decisions are in the best interests of the service user' (OT/U).

Discussions on what might constitute appropriateness became rather circular in that interviewees repeatedly ended up with 'the best interests of the service user'. But what constitutes the best interests of the service user in a world of rapidly expanding technological based care solutions and fiscal pressures on care services remains a moot point. Thus, best interests according to which analysis and on the basis of whose discourse; policy makers, technologists or service users (see Greenhalgh et al, 2012 for a fuller discussion)? Two of the sites ( $U$ and R1) had explicit ethical guides in place for front line staff. These were based on bio-medical frameworks (Beauchamp \& Childress, 2001) and had the limitations therein; there 
was no explicit acknowledgement of more recent ethical approaches such as an ethic of care (Gilligan, 1982; Tronto, 1994), although the urban site had a clear understanding of the role to be played by contextual ethics (Driver, 2007). However, since an ethic of care involves a disposition towards care, there may have been good ethical practice employed without the need for recourse to guidelines. The remaining site (R2) did not have explicit guidelines on ethics, relying instead on the ethical jud gement of care assessors. But when assessors are drawn from such a wide pool of practitioners (for example social care, nursing, allied health professions and housing) can there be cons is tency of ethical judgement - on issues such as risk, harm and privacy - across these different domains, especially as there is research (Irvine, Kerridge, McPhee, \& Freeman, 2002; Eccles, 2008; Cooper, 2012) which notes the potential for differences in value bases across these different professions?

Two responses (SW/R1 and HO/R1) argued that replacing human contact through the use of remote monitoring was more desirable as a type of care because it would be less intrusive for the service user. The discussions here were complex, ranging across contingencies of choice and availability of care, but also the contextual nature of these care decisions; for example, the potential for a service user to engage in religious observance uninterrupted by care workers was one reason offered $(\mathrm{HO} / \mathrm{R} 1)$ for the preference towards monitoring technology. This issue was made more complex for some practitioners by the parallel policy, being pursued across the United Kingdom, of personalised care, which ostensibly puts the issue of service user choice of care delivery at the heart of assessment. Thus to what extent could there be a refusal to engage with technology based care, if that was the client's choice, given the wider policy push for its adoption. As has been noted (Eccles et al, 2013) the only alternative choice here may be institutional care, not community care.

Overall the appropriateness of the application of technology was the key issue, reflecting the point raised by Pols and Moser (2010) about a false dichotomy between 'warm' care and 'cold' technology. One interviewee (T/R2) alighted on the enhanced quality of human contact that could be afforded by technology; thus whereas family members might previously have made multiple short visits to an elderly relative, the installation of monitoring sensors allowed on-going reassurance for the family affording much less frequent but more socially satisfying visits. Another practitioner (TA/R2) argued that moving people into residential care involved a much greater compromise on their dignity than putting sensors in their house and noted the often poor quality of existing care services delivery. So the baseline for discussion here is not actually a contrast between human care or technology based care; it is the actuality of these experiences. A discussion around these issues with computing technology designers following a symposium paper (Eccles, 2010, April) revealed a similar 'real world' approach. One computer technologist could see no point to the discussion on ethical issues around human and technological care since, in her view, in another decade technology would be the only option given demographic change, labour supply availability and public finances. In this vein the advocates for technology are pushing at an open door. The often bleak picture of care service delivery in the United Kingdom, as noted earlier by the Equality and Human Rights Commission (ECHR, 2011) is, for some practitioners and designers, a baseline for discussion. What is missing from this discussion is an attempt to stand back from the existing world of often poor care services and imagine how these might be reconfigured in terms of their delivery 
and funding. Telecare technologies are thus being seen here in the framework of current patterns of care delivery without more paradigm shifting questions about the future of demographic change and the configuration of care services.

The potential for resistance to the use of technology was raised by some interviewees. This was expressed (for example, $\mathrm{SW}(\mathrm{m}) / \mathrm{R} 1$ ) as arising from a lack of innovative thinking and over-familiarity with established patterns of work among frontline staff. It was also regarded simply as intuitive; thus one interviewee (SW/ R2) immediately responded to the issue of the relative merits of human care or technology based care:

Oh! human....we all need human contact [pause] ....on the other hand there are people who don't .... a minority don't.

Another reason offered for resistance to the use of technologies (SW/U) was the vested interests that might exist among independent care companies and care workers whose businesses and livelihoods were at stake. This argument was pursued at its strongest on the urban site where employment opportunities were otherwise scarce.

\subsection{Access to Technologies}

This aspect of the interviews looked at the allocation of technology-based care in terms of its accessibility and allocation across the three sites. As previously noted, different referral systems were in operation. The urban site used specifically trained technology advisers as gatekeepers in the assessment process. Thus a recommendation by a front line practitioner for technological solutions to care needs (which would have been prompted by a dedicated question in the care assessment form) would be reviewed by this gatekeeping process for appropriateness and consistency of recommendation. In one of the rural areas (R1) the assessment would go directly into the care management bud getary process, unmediated. It was acknowledged (PM/R1) that different professional disciplines might offer different recommendations by dint of background, familiarity with equipment and the immediate availability of time-limited funds associated with government funded Telecare Development Programmes. The third site (R2) did not operate a clear cut gatekeeping system but interviewees stressed that assessments which were complex were discussed with other technology assessors and would not be decided unilaterally.

Views on where, if any, a discrepancy in the allocation of technology resources might reside were different across different sites. Interviewees at rural site (R2) consistently stressed a generational divide; older people were more likely to be either uninterested or technophobic, raising the potential for tensions across families on the appropriateness of technological solutions to care needs. On the urban site the project manager stressed how much this was not clear cut and noted a highly technologically knowled geable older population in some instances. Access to computers was, however, problematic; an occupational therapist remarked that people familiar with computers at work were at a distinct advantage as they could more readily embrace the potential of telecare technologies. In this particular urban area - of industrial decline and inter-generational unemployment - this was an 'important issue'. It was also noted that lower income househo lds had switched from using landline telephones to basic 'pay as you go' mobile technology in order to reduce household costs. This technology might then preclude access to broadband based technologies (for example monitoring systems) as well as social 


\section{MInstitute ${ }_{\text {Mnk }}^{\text {Macrothink }}$}

networking sites. There was no consistency of policy across the sites on whether or not the telecare partnerships would subsequently underwrite the costs of landline installation to allow these technologies to be accessed; at best the cost of landline installation would be supported, but not the subsequent running costs (the reason for the switch to 'pay as you go' in the first instance). For one social work manager this was mitigated by a newer generation of technology; 'you can get pay as you go Blackberries these days' (SW(m)/ R1) but this leaves aside the question of costs. The commitment of the Scottish Government to install broadband in all new build and refurbished social housing would go some way to addressing the issue, but this remains an objective and leaves a (potentially growing) gap in accessibility to technology in the meantime. Subsequent policy development at the Urban site of this research has resulted in 3G based technology being made available for borrowing in local libraries as a way of including people who might otherwise be excluded from participating in this technological expansion on grounds of cost.

Much emphasis is put in policy discussions on the way in which technologies will supplement and not primarily replace human care services (Scottish Government, 2008). But it was pointed out in the interviews that this is clearly not the case in practice. Short visits to older people are being replaced, for example, by telephone enquires about well-being. These systems rely on self-reporting by older people of their status and are time limited to just such a (brief) dedicated enquiry. This arrangement offers the considerable advantage of allowing recipients to respond at a time of their choosing without pressure to be available and dressed or whatever other social norms might be expected. But it impacts upon two dimensions of a human presence in the care receiver's home; the ability to have a more extended conversation with the carer (with whom a relationship might have been built up over time) and a second opinion on the idea of whether or not a care receiver has indeed a reasonable level of self-reported well-being. Previous studies (Eccles, 2002) point to the role played by care workers in alerting other professionals - such as community nurses - to the need for an intervention (for example an older person claiming things are fine when observably they are not). That said, changes in social care provision over the past decade mean that the notion of a relationship developing between care givers and receivers may be anachronistic given the current fragmented state of older people's care in the United Kingdom. Technologies can replace these relational dimensions to an extent (through social networking and health monitoring by telehealth) but to what extent and how successfully needs further exploration. Lowe (2009) notes the potential of these remote technologies to increase isolation, with the attendant mental health issues, classically difficult to identify, that might arise. In organisational terms this may also mean that cost savings in social care may be transferred to additional costs in health care.

Refusal on the part of care receivers to countenance the use of technology raises the issue of choice. There were no clear answers here; one interviewee (HO/R1) explicitly thought the replacement of care staff by remote communication reasonable in that it freed up resources for more intensive care tasks. How people who refused technological solutions were dealt with returned to broader, circuitous, comments on the best interests of the client being met, without further detail. Older people's care needs - especially dementia - often change significantly over short periods of time (see Eccles et al, 2013 for a fuller discussion) and thus the appropriateness of technology-based care would need to be under regular review by health and social care 
professionals. This is not a given, in the current fiscal climate. As care receivers become older, and potentially more frail, the limits to technology-based care may have been met, in which case there needs to be an available supply of care staff to take over longer term. Of course technology has its limits in any case; the monitoring of care receivers' movements is no substitute for the physical lifting, hand ling and bathing that may be required. As noted earlier, monitoring has its uses here too; one interviewee (TA/ R2) commented that through the surveillance technology installed in people's homes,

'...we can tell that an hour of home care is only half an hour in some cases'.

\subsection{Telecare Performance Indicators}

As noted, Telecare project managers at all three sites cited finance as a key policy driver. Each project manager was responsible for collating figures on the use of telecare technologies and its impact on the various criteria of the Scottish Government performance indicators, such as hospital bed days saved and residential care averted through the use of telecare technologies. None of the project managers who were interviewed considered this recording of data to be straightforward. The Scottish Government's own evaluation of telecare (Scottish Government, 2009) uses, by its own admission, the least reliable of three possible methods to calculate one of its key indicators of 'hospital days saved' through the use of telecare. The actual methodology is worth quoting verbatim (present author's italics added); 'the evaluation relied on project managers or other staff working with the telecare users (e.g. those undertaking telecare assessments) to identify what they thought would otherwise have happened to the client at and subsequent to the time of issue of their telecare equipment. This information was then used to estimate the resources that would have been used if the telecare equipment had not been provided' (Scottish Government, 2009).

The project managers were sceptical that these figures could accurately be calculated. Front line practitioners noted the difficulty of estimating activity that 'might otherwise' have taken place. Indeed, the urban site that forms part of this research did not return some of the key performance figures on the grounds that they lacked robustness in their ability to portray, with reasonable accuracy, what the impact of using care technologies actually was on other services. Nonetheless, project managers were aware of the importance of collating figures on telecare usage, as these were a central element of meeting the performance indicators designed by the Scottish Government and on which performance ratings for telecare partnerships would in turn be allocated. The site which did not return the figures subsequently found itself categorised as performing relatively poorly based on the performance data, despite having its own case studies of good practice showcased by the Scottish Government. Such are the vagaries of performance indicators. If telecare activity in itself is a key element of performance, it raises ethical practice considerations around a tension between actual use and appropriateness of use, viz. sensitivity to risk, personal circumstances and engagement with families and carers. There is a further complicating factor here, in that the Scottish Government's own official 'partner' supplier of technology, the Tunstall corporation, offers packages of equipment where one element of equipment (for example, a community alarm) would be automatically supplemented by further technology (for example, passive infrared monitoring) whether or not specifically required. Telecare partnership managers at sites R1 and U expressed reservations about the 'package' approach to the use of telecare on the grounds of the tension it creates to 
the principle of sensitive, contextually located, assessment. This issue of available technologies was subsequently raised in other forums (for example, the author's engagement as part of the ESRC Making Research Count programme with telecare operational managers). Here the discussion centred on technology procurement and the propensity for purchasing from one supplier rather than operating in a more open fluid market, which, as some operational managers argued, might offer better tailored and more cost effective solutions to the needs of particular clients.

\section{Conclusion}

This paper notes that a prevailing discourse around technology use in health and social care in the United Kingdom is being shaped primarily by government and the technology suppliers what Greenhalgh (2012) notes as a 'political-industrial' nexus. The spaces for critical discussion lie outside this mainstream policy agenda. Research that does offer a critical perspective indicates a complexity in relationships between technologies and care recipients. In part this is because care relations themselves are being reconfigured between human beings and instead being increasingly mediated by technologies. It is also because responses to technology-based care with individuals are complex, frequently shifting and only partially understood by care practitioners. This paper has discussed the issues raised in pioneering ethnographic work from the UK and continental Europe and offers its own empirical research with telecare policy practitioners. Its findings adds to a literature which notes the ambiguities of telecare in its practice settings; often successful (but not necessarily, even then, by agreed criteria), frequently problematic, occasionally counter intuitive. The literature highlights the many layers of complexity; amongst service users who respond uniquely to the se technologies, amongst practitioners who respond unevenly to data gathering and interpretation, and amongst carers, whose motives for wishing telecare technologies to be used with those they care for may be benign but may represent an intrusion into others' privacy. In this arena of shifting notions about what constitutes beneficence and of largely unanswered questions around new ethical challenges to good practice, there appears to be one source of relative certainty of the success of these telecare technologies: policy makers and their 'partner' technology companies, for whom even inconclusive randomised control trials such as the WSD provide no barrier to claims of 'great success' and 'increased quality of life'. This paper argues that these hazards are not recognised enough in the ambitious policy by governments in the UK, nor openly acknowledged enough in the promotional literature of technology companies, and adds to the evidence about this complexity and uncertainty in its research with telecare practitioners. There are different views amongst practitioners, from the evidence presented here, on how relations of care might be affected, on the potential for encroachment of monitoring technologies into private spaces, and into ethical considerations around safety and individual liberty. These issues are played out across different assessing disciplines (although with no discernible consistency in this exploratory study) but also between urban and rural settings - although, again, without any clear consistency. As noted at the outset, Pols and Willems (2011) argue, of telecare strategy in the United Kingdom, 'implementing telecare technologies on a large scale and on a top-down basis, as is done in the UK, [is] a hazardous investment'. The research in this paper offers more evidence of the hazards of policy assumptions as they contend with practice complexity. It leaves a need, as recommended by the Whole System Demonstrator 
research (Cartwright et al, 2013) for more qualitative research around care technology users, carers and care practitioners with which to reveal more sensitively the human impact and ethical complexities of care practice using telecare technologies.

\section{References}

Audit Commission. (2004). Implementing telecare. London: Audit Commission.

Beauchamp, L., \& Childress, A. F. (2001). Principles of biomedical ethics (5th ed.). Oxford: Oxford University Press.

Blaschke, C., Freddolino, P., \& Mullen, E. (2009). Ageing and technology: A review of the research literature. British Journal of Social Work, 39, 641-656. http://dx.doi.org/10.1093/bjsw/bcp025

Bouma, H. (2010). Professional ethics in gerontechnology: A pragmatic approach. Gerontechnology, 9(4), 429-432. http://dx.doi.org/10.4017/gt.2010.09.04.018.00

Cameron, D. (2011, December 6). We've got to change the way we innovate, the way that we collaborate, and the way that we open up the NHS (transcript of speech, exactly as it was delivered). $\quad$ Retrieved from https://www.gov.uk/government/speeches/pm-speech-on-life-sciences-and-opening- up-the-n hs.

Cartwright, M., Hirani, S., Rixon, L., Beynon, M., Doll, H., Bower, P., . . Newman, S. (2013). Effect of telehealth on quality of life and psychological outcomes over 12 months (Whole Systems Demonstrator telehealth questionnaire study): Nested study of patient reported outcomes in a pragmatic, cluster randomised control trial. [Open access publication]. British Medical Journal. http://dx.doi.org/10.1136/bmj.f653

Cooper, A. (2012). Complexity, identity, failure: Contemporary challenges to working together. In J. Forbes, \& C. Watson (Eds.), The transformation of children's services (pp. 15-23). New York: Routeledge.

Department of Health. (2012a). A concordat between the Department of Health and the telehealth and telecare industry. Retrieved from https://www.gov.uk/government/uploads/system/uploads/attachment_data/file/216757/Conco rdat-3-million- lives.pdf.

Department of Health. (2012b). Telehealth and telecare could save NHS £1.2 billion (press release).

Retrieved

from

https://www.gov.uk/government/news/telehealth-and-telecare-could-save-nhs-1-2-billion.

Draper, B., \& Sorrell, T. (2012). Telecare, remote monitoring and care. Bioethics, 27, 365-372. http://dx.doi.org/10.1111/j.1467-8519.2012.01961.x

Driver, J. (2007). Ethics: The fundamentals. Oxford: Blackwell.

Eccles, A. (2002). The provision of services for older people in North Ayrshire. Unpublished report. Centre of Gerontology and Health Studies, University of Paisley, Paisley, UK. 
Eccles, A. (2008). Singe shared assessment: The limits to 'quick fix' implementation. Journal of Integrated Care, 16(1), 22-30. http://dx.doi.org/10.1108/14769018200800005

Eccles, A. (2010a). Ethical considerations around the implementation of telecare technologies. Journal of Technology in Human Services, 28(1-2). http://dx.doi.org/10.1080/15228831003770759

Eccles, A. (2010b). Ethical is sues in the implementation of telecare policy. Gerontechnology, 9(2), 83-84. http://dx.doi.org/10.4017/gt.2010.09.02.034.00

Eccles, A. (2010, April). Ethical considerations around the use of telecare technologies. Paper presented at the SICSA Socio-Technical Systems Conference, Glasgow, University of Glasgow.

Eccles, A., Damadoran, L., Harding, I., Olphert, W., \& Gilhooly, M. (2013). Assistive technologies: Ethical practice, ethical research and quality of life. In A. Sixsmith, \& G. Gutman (Eds.), Assistive technologies for active aging (pp. 47-68). New York: Springer.

EFORTT. (2011). EFORTT: Ethical frameworks for telecare technologies for older people at home: Final research report. Retrieved from http://www.lancaster.ac.uk/efortt/documents/Deliverable\%207\%20Final\%20Research\%20rep ort.pdf.

Equality and Human Rights Commission. (2011). Close to home: An inquiry into older people and human rights in home care. Retrieved from http://www.equalityhumanrights.com/uploaded_files/homecareFI/home_care_report.pdf

European Commission. (2013). Coping with an ageing population: Learning from good eHealth and telecare practices: The eCare benchmarking study. Retrieved from http://ec.europa.eu/digital-agenda/en/news/ecare-benchmarking-coping-ageing-population- $\%$ E2\%80\%93-learning-good-ehealth-and-tele-care-practices

Gilligan, C. (1982). In a different voice: Psychological theory and women's development. Cambridge: Harvard University Press.

Goodwin, N. (2011, March 15). Can we justify the investment in telehealth and telecare? [The King's Bund Blog]. $\quad$ Retrieved from http://www.kingsfund.org.uk/blog/2011/03/can-we-justify-investment-telehealth-and-telecare Greenhalgh, T. (2012). Whole System Demonstrator trial: policy, politics, and publication ethics. [Open access letter]. British Medical Journal. http://dx.doi.org/10.1136/bmj.e5280

Greenhalgh, T., Procter, R., Wherton, J., Sugarhood, P., \& Shaw, S. (2012). The organising vision for telehealth and telecare: discourse analysis. [Open access article]. British Medical Journal. http://dx.doi.org/10.1136/bmjopen-2012-001574

Greenhalgh, T., Wherton, J., Sugarhood, P., Hinder, S., Procter, R., \& Stones, R. (2013). What matters to older people with assisted living needs? A phenomenological analysis of the use and 
non-use of telehealth and telecare. Social Science \& Medicine, 93, 86-94. http://dx.doi.org/10.1016/j. socscimed.2013.05.036

Henwood, M. (1994). Fit for change? Snap shots of the community care reforms one year on. Leeds: Community Care Division, Nuffield Institute for Health.

Innes, A., Morice, A., \& Faruqi, S. (2012, June 29). Re: Effect of telehealth on use of secondary care and mortality: findings from the Whole System Demonstrator cluster randomised trial. [Open access response]. British Medical Journal. http://dx.doi.org/10.1136/bmj.e3874

Irvine, R., Kerridge, I., McPhee, J., \& Freeman, S. (2002). Interprofessionalism and ethics: Consensus or clash of cultures? Journal of Interprofessional Care, 16(3), 199-210. http://dx.doi.org/10.1080/13561820220146649

Kamphof, I. (2013). Samenwerken. Over mensen en dingen in zorgnetwerken. Ethische Perspectieven, 23(2), 124-136.

Kamphof, I. (2013, May). The observation of technology users using technologies. Paper presented at the The Use of Assistive Technologies in Social Care: Addressing the Social Dimensions. Symposium of the Scottish Universities Insight Institute, Glas gow, University of Strathclyde.

Lintern, S. (2012, July 27). Survey finds 91pc of people have not heard of telehealth. Health Services Journal. Retrieved from http://www.hsj.co.uk/news/survey-find s-91pc-of-people-have-not-heard-of-telehealth/504757 9.article\#.UlRRjtKsim4

Loader, B., Hardey, M., \& Keeble, L. (Eds.). (2009). Digital welfare for the third age. London: Routledge.

Lowe, C. (2009). Beyond telecare: The future of independent living. Journal of Assistive Technologies, 3(1), 21-23. http://dx.doi.org/10.1108/17549450200900004

McCreadie, C., \& Tinker, A. (2005). The acceptability of assistive technology to older people. Ageing and Society, 25, 91-110. http//dx.doi.org/10.1017/S0144686X0400248X

Meagher, G., \& Parton, N. (2004). Modernising social work and the ethics of care. Social Work and Society, 2(1), 10-27. Retrieved from http://www.socwork. net/sws/article/view/237/297

Miles, M. B., \& Huberman, A. M. (1994). Qualitative data analysis: An expanded sourcebook (2nd ed.). Thousand Oaks: Sage Publication.

Mort, M., Roberts, C., \& Callén, B. (2013). Ageing with telecare: Care of coercion in austerity? $\begin{array}{lllll}\text { Sociology of Health } \quad \& \quad \text { Illness, } & 35(6), & \text { 799-812. }\end{array}$ http://dx.doi.org/10.1111/j.1467-9566.2012.01530.x

Mort, M., Roberts, C., \& Milligan, C. (2009). Ageing, technology and the home: A critical project. European Journal of Disability Research, 3(2), 85-89. http://dx.doi.org/10.1016/j.alter.2009.02.004 
Moser, I. (2012, September). Telecare: New values, ideals and modes of caring. Paper presented at the Critical care: Advancing an ethic of care in theory and practice, Brighton, University of Brighton. https://student.brighton.ac.uk/videos/newvideos.php?ID=1608

Newman, S. (2011, March). Insight into the WSD programme. Paper presented at the International Congress on Telehealth and Telecare, London, The King's Fund. http://www.kingsfund.org.uk/audio-video/stan-newman-insight-wsd-programme

Oudshoorn, N. (2011). Telecare technologies and the transformation of healthcare. Basingstoke: Palgrave. http://dx.doi.org/10.1057/9780230348967

Pols, J. (2012). Care at a distance. Amsterdam: Amsterdam University Press.

Pols, J., \& Moser, I. (2009). Cold technologies versus warm care? On affective and social relations with and through care technologies European Journal of Disability Research, 3, 159-178. http://d x.doi.org/10.1016/j.alter.2009.01.003

Pols, J., \& Willems, D. (2011). Innovation and evaluation: Taming and unleashing telecare technology. Sociology of Health \& Illness, 33(3), 484-498. http://dx.doi.org/10.1111/j.1467-9566.2010.01293.x

Rapley, T. (2011). Some pragmatics of data analysis. In D. Silverman (Ed.), Qualitative research: Issues of theory, method and practice (3rd ed., pp. 273-290). London: Sage.

Rourke, L., Anderson, T., Garrison, D. R., \& Archer, W. (2001). Methodological issues in the content analysis of computer conference transcripts. International Journal of Artificial Intelligence in Education, 12(1), 1-16. $\quad$ Retrieved from http://ijaied.org/pub/951/file/951_paper.pdf

Scottish Government. (2008). Telecare in Scotland: Benchmarking the present, embracing the future. Edinburgh: Crown Copyright Retrieved from http://lx.iriss.org.uk/sites/default/files/resources/1204629144-TDP\%20-\%20TDB\%20-\%2015 \%20Feb\%202008\%20-\%20Benchmarking\%20Report.pdf.

Scottish Government. (2009). Evaluation of the telecare development programme: Final report. Retrieved from www.jitscotland.org.uk/...B59058\%20Fina1\%20Report\%20low\%20res.pdf.

Scottish Government. (2010). Scottish Government urban rural classification 2009-2010. Retrieved from http://www.scotland.gov.uk/Publications/2010/08/2010UR.

Scottish Government. (2012). A National telehealth and telecare delivery plan for Scotland to 2015: Driving improvement, integration and innovation. Retrieved from http://www.scotland.go v.uk/Resource/0041/00411586.pdf.

Söderlund, R. (2004). The role of information and communication technology in home services: Telecare does not satisfy the needs of the elderly. Health Informatics Journal, 10(2), 127-137. http://dx.doi.org/10.1177/1460458204042237 


\section{Macrothink}

Issues in Social Science ISSN 2329-521X 2013, Vol. 1, No. 1

Steyaert, J., \& Gould, N. (2009). Social Work and the changing face of the digital divide. British Journal of Social Work, 39(4), 740-753. http://dx.doi.org/10.1093/bjsw/bcp022

Tronto, J. (1994). Moral Boundaries: A political argument for an ethic of care. London: Routledge.

Tronto, J. (2010). Creating caring institutions: Politics, plurality, and purpose. Ethics and Social Welfare, 4(2), 158-171. http//dx.doi.org/10.1080/17496535.2010.484259

Twigg, J. (1999). The spacial ordering of care: public and private in bathing support at home. Sociology of Health \& Illness, 21(4), 381-400. http//d x.doi.org/10.1111/1467-9566.00163

Yeandle, S., \& Fry, G. (2010). The potential of ICT in supporting domiciliary care in England. Seville: European Commission. Retrieved from http://ipts.jrc.ec.europa.eu/publications/pub.cfm?id=3019

\section{Copyright Disclaimer}

Copyright reserved by the author(s).

This article is an open-access article distributed under the terms and conditions of the Creative Commons Attribution license (http//creativecommons.org/licenses/by/3.0/). 